Max-Planck-Institut für demografische Forschung

Max Planck Institute for Demographic Research

Konrad-Zuse-Strasse 1 - D-18057 Rostock = Germany = Tel +49 (0) 3812081 - 0 - Fax +49 (0) 3812081 - 202 - www.demogr.mpg.de

MPIDR Technical Report TR 2018-005 I October 2018

\title{
An Educational Simulation Tool \\ to Enhance the Understanding of Population Dynamics
}

RainerWalke I walke@demogr.mpg.de

Daniel Ciganda I ciganda@demogr.mpg.de

Sebastian Klüsener

For additional material see www.demogr.mpg.de/tr

\footnotetext{
This technical report has been approved for release by: Mathias Lerch (lerch@demogr.mpg.de), Deputy Head of the Laboratory of Fertility and Well-Being.

(c) Copyright is held by the authors.
} 
An Educational Simulation Tool to Enhance the Understanding of Population Dynamics Rainer Walke ${ }^{*}$, Daniel Ciganda ${ }^{*}$, Sebastian Klüsener ${ }^{* * * *}$

* Max-Planck-Institute for Demographic Research

${ }^{* *}$ Federal Institute for Population Research, Vytautas Magnus University

\begin{abstract}
There is a dearth of software tools targeted at the general public that provide users with an intuitive understanding of population dynamics and the underlying demographic processes (fertility, mortality, and migration). This existing gap motivated us to implement such a tool in the software package NetLogo. In this technical working paper, we describe the technical specifications of the tool and provide access to the underlying NetLogo code. In addition, we outline the lessons users could learn from our educational tool.
\end{abstract}

Keywords: simulation, population age structure, population projections, population dynamics 


\section{Motivation}

Population dynamics and their implications for the size and age structure of populations are of considerable relevance for public debates (e.g., Coulmas 2007, Elmendorf and Sheiner 2000, Greenhalgh 2013). High fertility can lead to youth bulges (Fuller 1995) and strong population growth if mortality and out-migration are low. Low fertility, on the other hand, is likely to lead to population aging and shrinking. Again, it is important to emphasize that population aging is driven not only by fertility levels, but also by mortality trends and migration dynamics. While there have been public debates about the direct demographic implications of these processes - such as about how these processes affect the size and age structure of particular populations in the short, medium, and long run - the main focus of public interest has been on the (potential) social and economic implications of these developments. For example, youth bulges might lead to instability due to high youth unemployment, while population aging could endanger the sustainability of welfare systems.

The educational simulation tool presented in this paper has been developed to provide non-scientific users with an intuitive understanding of how fertility, mortality, and migration processes interact in producing changes in the age structure and size of populations. By altering fertility, mortality, and migration levels, users are, for example, able to explore to what degree changes in fertility could be counterbalanced by changes in mortality and migration. Although other similar educational tools are available ${ }^{1}$, to the best of our knowledge these tools focus exclusively on fertility and mortality patterns. By also taking simple migration dynamics into account, our simulation tool provides users with the opportunity to develop a better understanding of pressing contemporary issues, like the arrival of migrants and the effect this development has on the age structure and the evolution of a population as a whole.

In addition to allowing users to alter fertility, mortality, and migration rates in order to explore how these changes affect population development, the tool is designed to raise awareness among users about the pace of demographic change. This, we hope, will support users in developing a more skeptical scientific perspective on apocalyptic warnings about "population bombs" (Ehrlich 1978) or "demographic suicides" (Prichet and Viarengo 2013).

There are a wide range of software platforms on which such a simulation tool could be built. We decided to implement the tool with NetLogo simulation software (Wilensky 1999), because this platform makes it easy to implement sliders and buttons that allow users to easily change the parameter settings of the model. These changes are then immediately reflected in the model dynamics. Such features would, for example, be more difficult to implement in $\mathrm{R}$, which we might have chosen if we had wanted to use such a simulation of population dynamics primarily for scientific purposes.

\section{Data and specification of the tool}

As the tool was initially developed for the German public, we use data for Germany in the code presented here. Included in these data are the female age-specific period fertility rates for 2013 (HFD 2018); the period mortality rates by single-year ages for Germany in the same year (HMD 2018); and the official statistical data on the balance of in- and out-migration counts from and to Germany by single-year ages, again in 2013 (Klüsener et al. 2018). Our use of period fertility rates raises the issue that these rates are artificially depressed due to the ongoing postponement process to higher ages at childbirth. For example, in Germany in 2012, the tempo-adjusted total fertility rate (Bongaarts and Feeney 1998) was 1.59, while the non-adjusted rate was 1.41 (HFD 2018). By keeping the level of

\footnotetext{
${ }^{1}$ https://www.ined.fr/en/everything about population/population-games/tomorrow-population/ https://www.learner.org/courses/envsci/interactives/demographics/demog.html
} 
fertility constant at the period rates for 2013, the pace of population aging and shrinking in the simulations is, for example, likely to be overestimated. Thus, if users would like to freeze fertility at current cohort fertility levels, they would need to choose slightly higher fertility levels.

For the migration data, we decided to use counts instead of rates, as we believe that migration is less dependent on the population already living in the country. This choice is also in line with the assumptions about future migration in absolute numbers that are used by the German Federal Statistical Office for implementing population projections (Pötzsch and Rößger 2015). While we focus on Germany, data for other countries could be easily integrated as well.

The initial population structure represents Germany in 2013. The population age structure by singleyear ages ("population pyramid") becomes visible in the so-called world window as soon as the [setup] button is pressed. Pressing [reset standard values] resets all sliders to the default values. Our fertility and mortality patterns by age are derived from the age-specific rates recorded in 2013. Sliders allow the users to modify these fertility and mortality rates. For reasons of simplicity, we have chosen to keep the age structure constant, so that all the age-specific fertility or mortality rates are multiplied by the same factor if users decide to adjust the fertility or mortality levels. The fertility slider allows users to select the number of children women will have at the end of their reproductive lives in the simulation (sum of age-specific rates). In contrast, the mortality factor denotes the annual reduction or gain in the mortality rates. For migration, we offer two different options. In the first option, users can apply the age-specific net migration rates as they were recorded in 2013. In the second option, it is possible to increase the cohort size at age 20 by $20 \%$ in response to an immigration wave. Thus, users are able to explore how singular in-migration waves affect population structures in the long run. By making multiple clicks, users can increase the cohort size multiple times. For convenience, both migration options have a switch for automatic annual reapplication.

In addition, users can specify a cohort they want to follow. This could, for example, be a user's own cohort. A yellow dot then appears in the center of the world window to indicate the position of this cohort in the population pyramid. This yellow dot moves upward as the cohort ages. Additional monitor windows provide information on the changes in the total population and the year that has been reached.

\section{Discussion and Conclusion}

The software tool has been tested by school classes and by visitors attending an open door day at the MPIDR. For testing purposes, a German language version of the tool was developed. While the overall feedback was positive, it became clear during the testing phase that it was helpful to have a person with demographic background knowledge around to provide initial assistance to the users. Once the users had a basic understanding of the tool, they were able to handle it independently. The dimension that generated the most interest among the participants in this phase was the potential effect of migration in slowing down the pace of population aging. We therefore believe that even though our tool presents only a rudimentary sketch of this process, it can help users to develop a more nuanced understanding of a hotly debated topic.

A number of extensions of this tool are possible. As well as including data for different countries that are facing different demographic challenges, we could add modifications that allow users to adjust the age-specific schedules of fertility, mortality, and migration. This would, for example, permit users to explore how fertility postponement or changes in the modal age or lifespan variation of mortality (Vaupel et al. 2011) affect population dynamics. It might also be interesting to implement the option to simulate (massive) emigration waves if the tool is used for countries that register substantial emigration. More sophisticated extensions might enable users to model trends separately for different 
educational groups (Kc et al. 2010). Such extensions would, however, require detailed data that are not easy to obtain for many countries, including for Germany. We would be very grateful if researchers built upon our work by implementing more sophisticated versions of our simulation tool, either in NetLogo or in other software packages. 


\section{References}

Bongaarts, J., \& Feeney, G. (1998). On the Quantum and Tempo of Fertility. Population and Development Review, 24(2), 271-291. doi:10.2307/2807974

Coulmas, F. (2007). Population Decline and Ageing in Japan: The Social Consequences. London: Routledge.

Ehrlich, P. R. (1978). The Population Bomb. New York: Ballantine.

Elmendorf, D. W., \& Sheiner, L. M. (2000). Should America save for its old age? Fiscal policy, population aging, and national saving. Journal of Economic Perspectives, 14(3), 57-74.

Fuller, G. (1995). The demographic backdrop to ethnic conflict: A geographic overview. In: Central Intelligence Agency (ed.). The Challenge of Ethnic Conflict to National and International Order in the 1990s (pp.151 -156), Washington: Central Intelligence Agency.

Greenhalgh, S. (2013). Patriarchal demographics? China's sex ratio reconsidered. Population and Development Review, 38(supplement), 130-149.

Kc, S., Barakat, B., Goujon, A., Skirbekk, V., Sanderson, W., \& Lutz, W. (2010). Projection of populations by level of educational attainment, age, and sex for 120 countries for 2005-2050. Demographic Research, 22(Art 15), 383-472.

Klüsener, S., Grigoriev, P., Scholz, R. D., \& Jdanov, D. A. (2018). Adjusting inter-censal population estimates for Germany 1987-2011: Approaches and impact on demographic indicators. Comparative Population Studies, 43(2018): 31-64.

Pötzsch, O., \& Rößger, F. (2015). Bevölkerung Deutschlands bis 2060. 13. koordinierte Bevölkerungsvorausberechnung. Wiesbaden: Statistisches Bundesamt.

Pritchett, L., \& Viarengo, M. (2013). Why demographic suicide? The puzzles of European fertility. Population and Development Review, 38(supplement), 55-71.

Vaupel, J. W., Zhang, Z., \& van Raalte, A. A. (2011). Life expectancy and disparity: An international comparison of life table data. BMJ open 1:e000128

Wilensky, U. 1999. NetLogo. http://ccl.northwestern.edu/netlogo/. Center for Connected Learning and Computer-Based Modeling, Northwestern University. Evanston, IL.

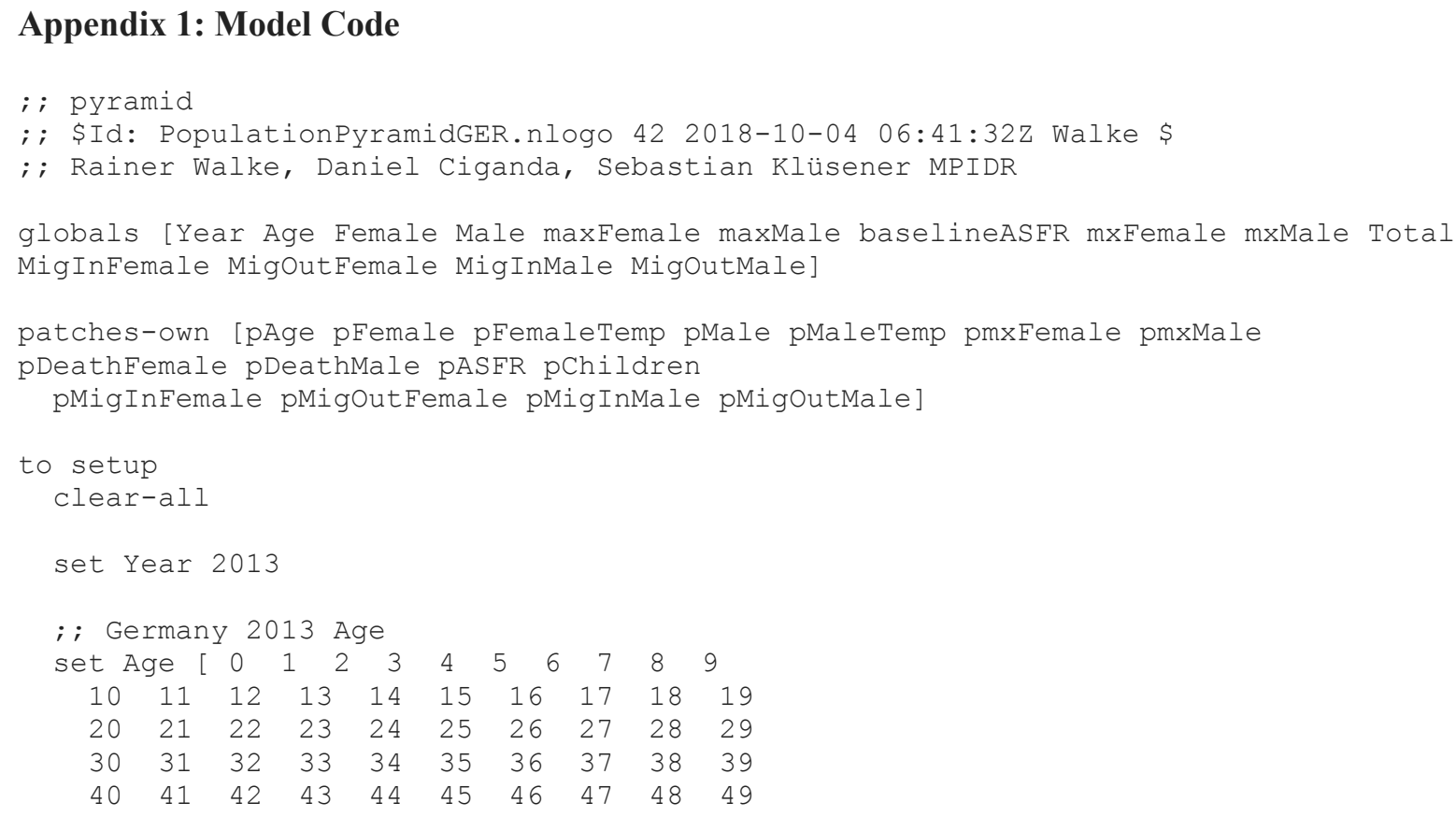




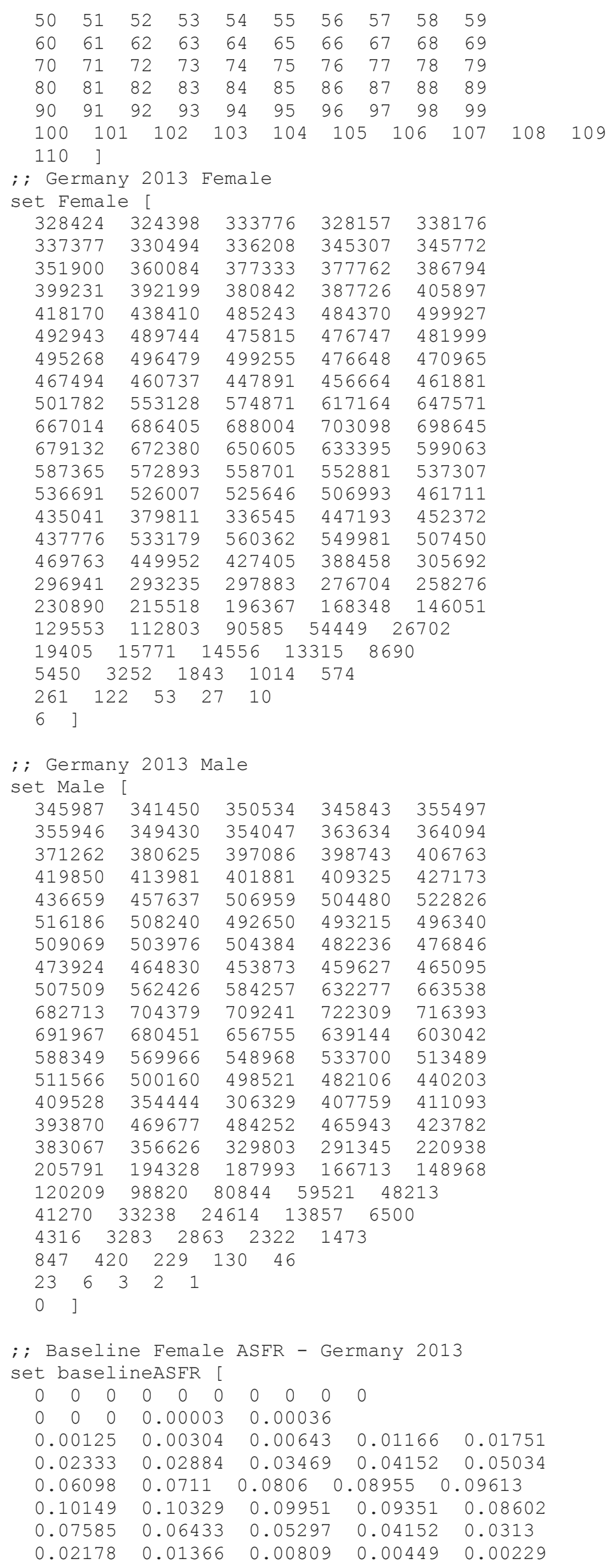




\begin{tabular}{|c|c|c|c|c|c|c|c|c|c|c|}
\hline \multicolumn{3}{|c|}{0.00109} & \multicolumn{3}{|c|}{0.00056} & \multicolumn{3}{|c|}{0.00026} & 0.00013 & 0.00009 \\
\hline & 00 & & 0 . & 00 & & & 00 & & 0.00001 & 0 \\
\hline 0 & 0 & 0 & 0 & 0 & 0 & 0 & 0 & 0 & 0 & \\
\hline 0 & 0 & 0 & 0 & 0 & 0 & 0 & 0 & 0 & 0 & \\
\hline 0 & 0 & 0 & 0 & 0 & 0 & 0 & 0 & 0 & 0 & \\
\hline 0 & 0 & 0 & 0 & 0 & 0 & 0 & 0 & 0 & 0 & \\
\hline 0 & 0 & 0 & 0 & 0 & 0 & 0 & 0 & 0 & 0 & \\
\hline 0 & 0 & 0 & 0 & 0 & 0 & ] & & & & \\
\hline
\end{tabular}

; ; Germany $2013 \mathrm{mx}$ Female set mxFemale [

\begin{tabular}{|c|c|c|c|c|}
\hline & 0.000271 & 0.000112 & 0.000112 & 0.00007 \\
\hline 094 & 0.000087 & 0.000066 & 0.000079 & 0005 \\
\hline & 0.000056 & 0.000087 & 0.000079 & 0.000115 \\
\hline 38 & 00157 & 0.000166 & 0.000182 & 020 \\
\hline 09 & 181 & 016 & 0.000227 & 0.0 \\
\hline & 222 & 226 & 246 & 29 \\
\hline 2 & 306 & 355 & 0 . & 0. \\
\hline & 0 . & 0 . & 0 . & 0 \\
\hline & 0 . & 0 . & & \\
\hline & 0 . & 0 . & & 25 \\
\hline & 0 . & 0 . & & 04 \\
\hline & 0 . & 0 . & & 384 \\
\hline & 82 & 0 . & 0 . & 653 \\
\hline & 0 . & 0 . & 789 & 371 \\
\hline & 43 & 84 & 0 . & 0. \\
\hline & 0.02318 & 0.026469 & 0.031616 & 0. \\
\hline & 0 . & 0 . & 0 . & \\
\hline & 0 . & 0.1 & 0.1 & 0 . \\
\hline & 227 & 0.2 & 0.25834 & 0.23 \\
\hline & & 0 . & 0.410442 & 715 \\
\hline & 612 & 0.52139 & 0.559208 & 0.608025 \\
\hline & & 0.570523 & 0.821505 & 0.91607 \\
\hline & & & & \\
\hline
\end{tabular}

; ; Germany $2013 \mathrm{mx}$ Male set mxMale [

$\begin{array}{lllll}0.003644 & 0.000307 & 0.000166 & 0.000135 & 0.000097 \\ 0.000117 & 0.000077 & 0.000097 & 0.00008 & 0.000124\end{array}$

$\begin{array}{lllll}0.000062 & 0.000061 & 0.00008 & 0.000095 & 0.000099\end{array}$

$\begin{array}{lllll}0.00016 & 0.000238 & 0.000282 & 0.000443 & 0.000453\end{array}$

$\begin{array}{llllll}0.000435 & 0.000446 & 0.000426 & 0.000467 & 0.000461\end{array}$

$\begin{array}{lllll}0.000516 & 0.000544 & 0.000478 & 0.00057 & 0.000572\end{array}$

$\begin{array}{llllll}0.000658 & 0.000641 & 0.000669 & 0.000704 & 0.000814\end{array}$

$\begin{array}{lllll}0.000857 & 0.000836 & 0.000881 & 0.001014 & 0.001201\end{array}$

$\begin{array}{lllll}0.001217 & 0.001306 & 0.001459 & 0.001688 & 0.001818\end{array}$

$\begin{array}{lllll}0.002098 & 0.002403 & 0.002556 & 0.00293 & 0.00334\end{array}$

$\begin{array}{lllll}0.003595 & 0.004281 & 0.004751 & 0.005344 & 0.005982\end{array}$

$\begin{array}{llllll}0.00655 & 0.007056 & 0.007974 & 0.008871 & 0.009478\end{array}$

$\begin{array}{lllll}0.01048 & 0.011193 & 0.011982 & 0.013041 & 0.014119\end{array}$

$\begin{array}{lllll}0.015249 & 0.016663 & 0.017911 & 0.020125 & 0.021197\end{array}$

$\begin{array}{lllll}0.022404 & 0.025119 & 0.026439 & 0.02989 & 0.032203\end{array}$

$\begin{array}{lllll}0.035366 & 0.040286 & 0.044649 & 0.051918 & 0.056072\end{array}$

$\begin{array}{llllll}0.063882 & 0.07311 & 0.084006 & 0.094824 & 0.106097\end{array}$

$\begin{array}{lllll}0.117804 & 0.130485 & 0.148224 & 0.166583 & 0.185359\end{array}$

$\begin{array}{lllll}0.204738 & 0.234709 & 0.254843 & 0.308031 & 0.259591\end{array}$

$\begin{array}{lllll}0.344735 & 0.378649 & 0.392058 & 0.493306 & 0.475073\end{array}$

$\begin{array}{lllll}0.602986 & 0.59679 & 0.507168 & 0.68606 & 0.689942\end{array}$

$\begin{array}{lllll}1.087985 & 0.831354 & 0.495868 & 2.598477 & 2.554945\end{array}$ $6 \quad]$

;; Germany 2013 MigIn Female

set MigInFemale [

$\begin{array}{lllll}3126 & 6509 & 6181 & 5789 & 5546\end{array}$

$\begin{array}{lllll}5341 & 4782 & 4469 & 4043 & 4056\end{array}$

$\begin{array}{lllll}3857 & 3522 & 3470 & 3364 & 3101\end{array}$

$\begin{array}{lllll}3223 & 3914 & 4007 \quad 7208 \quad 12636\end{array}$

$\begin{array}{lllll}16914 & 19982 & 21212 & 22173 & 20902\end{array}$

$\begin{array}{lllll}19594 & 17285 & 15876 & 14670 & 13471\end{array}$ 


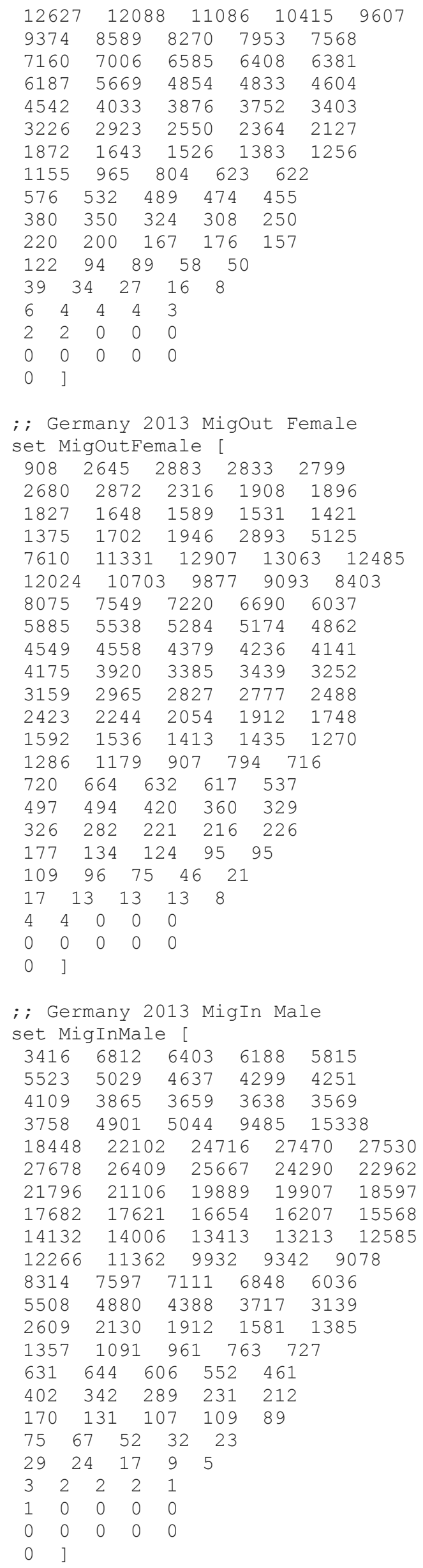




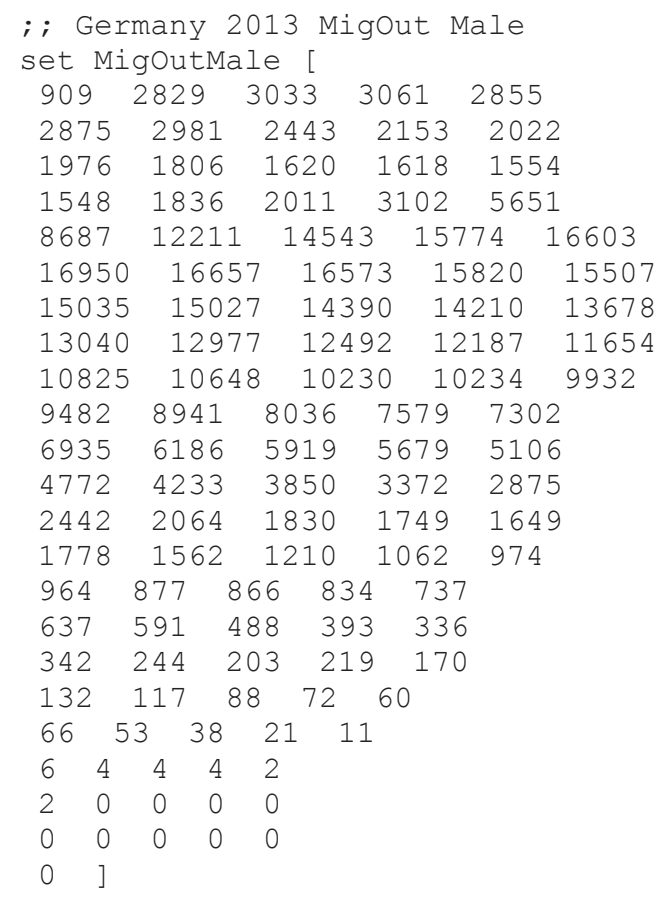

set maxFemale 800000

set maxMale 800000

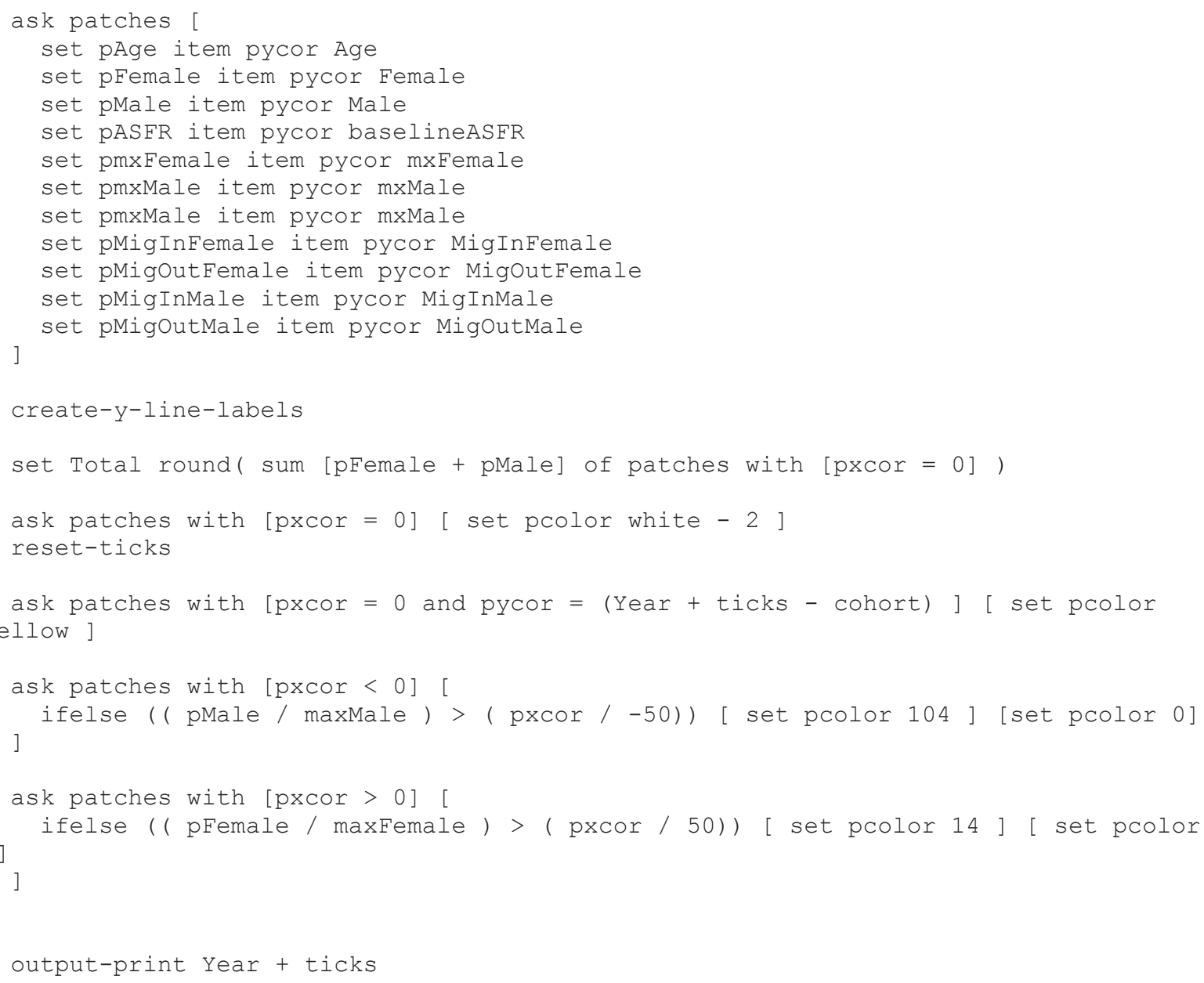




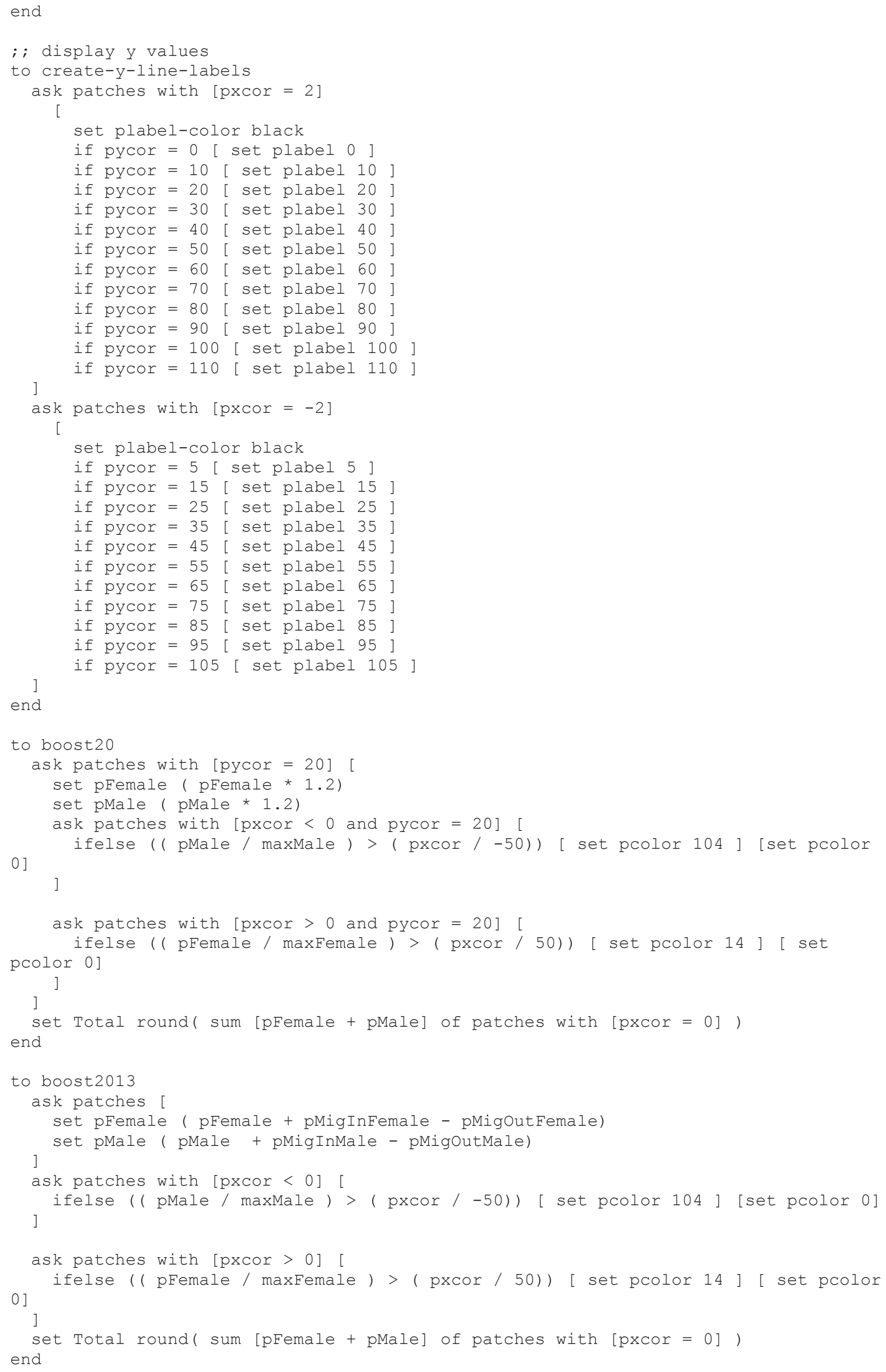




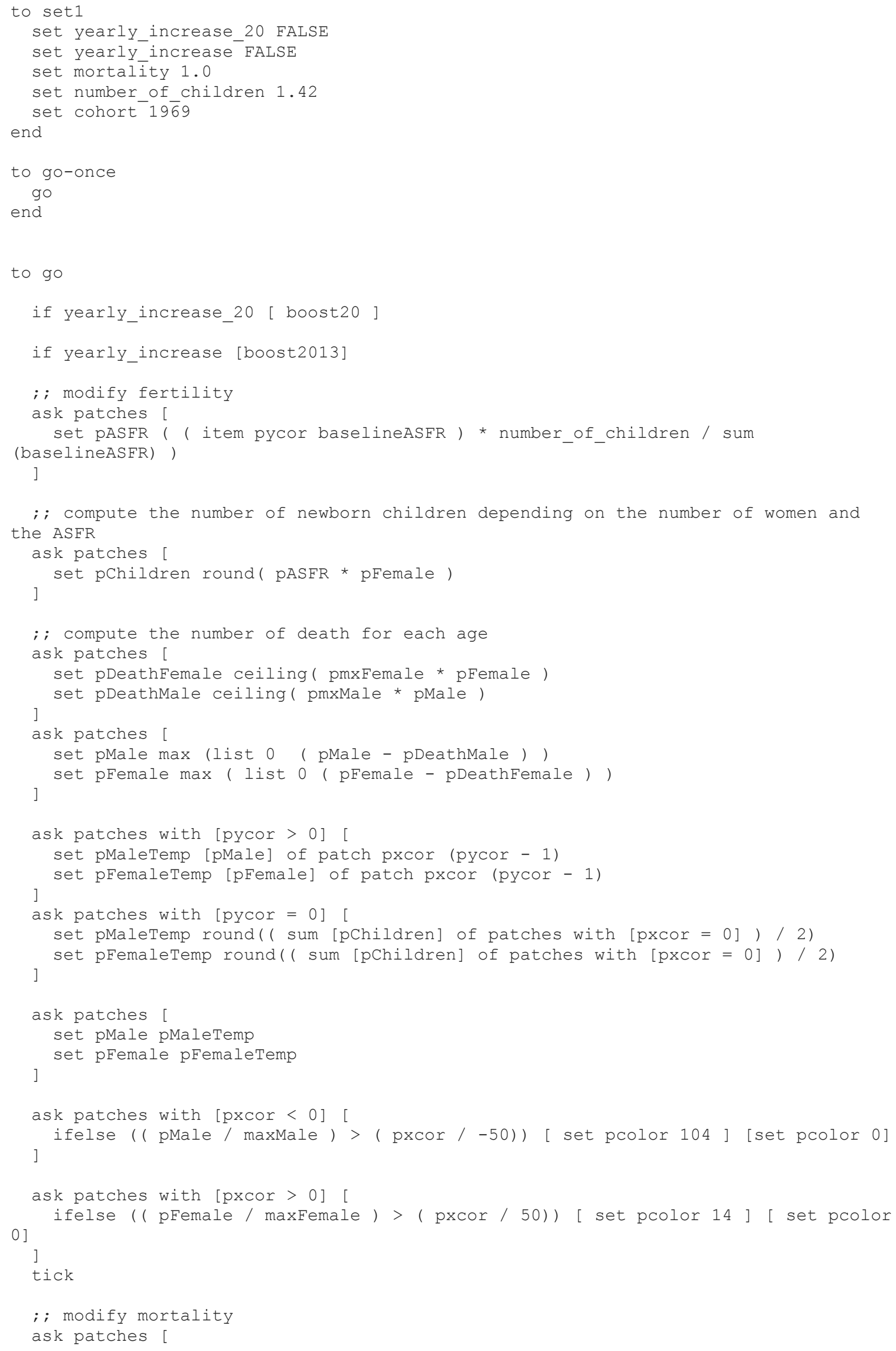


set pmxMale ( pmxMale * mortality )

]

set pmxFemale ( pmxFemale * mortality )

ask patches with $[$ pxcor $=0$ ] [ set pcolor white -2 ]

ask patches with $[$ pxcor $=0$ and pycor $=$ (Year + ticks - cohort) ] [ set pcolor yellow

set Total round ( sum [pFemale + pMale] of patches with [pxcor $=0]$ )

output-print Year + ticks

end 